\title{
СУБЪЕКТИВНАЯ ОЦЕНКА БОЛИ В СТРУКТУРЕ НЕМОТОРНЫХ ПРОЯВЛЕНИЙ БОЛЕЗНИ ПАРКИНСОНА
}

\author{
(С) Никишина В.Б., Шутеева Т.В., Запесоцкая И.В., Петраш Е.А. \\ Курский государственный медицинский университет, Курск \\ E-mail: petrash@mail.ru
}

\begin{abstract}
В статье представлены результаты исследования субъективной оценки боли в структуре немоторных проявлений болезни Паркинсона (БП). При исследовании чувствительности у пациентов получены результаты, указывающие на гиперчувствительность, проявляющуюся как при точности локализации прикосновений, так и при переносе прикосновения с одной руки на другую, также выявлен высокий уровень дискриминационной чувствительности. Анализ эмоционального отношения к боли и лингвосемантического означивания сенсорного ощущения боли у пациентов с БП свидетельствует о высокой степени дифференцированности семантических единиц. Практическая значимость результатов проведенного исследования заключается в том, что впервые на уровне эмпирической аргументации представлена взаимосвязь субъективного ощущения боли, чувствительности и эмоциональных реакций. Сенсорно-болевые ощущения являются ранними маркерами домоторной стадии (I-II стадии) БП. Их сочетанность с депрессивными проявлениями позволяет выявить манифестацию заболевания на ранних этапах.
\end{abstract}

Ключевые слова: болезнь Паркинсона, болевой синдром, немоторные нарушения, интрацептивные ощущения, дескрипторы интрацептивных ощущений.

\section{SUBJECTIVE PAIN EVALUATION IN THE STRUCTURE OF NONMOTOR MANIFISTATIONS OF PARKINSON'S DISEASE}

Nikishina V.B., Shuteeva T.V., Zapesotskaya I.V., Petrash E.A.

Kursk State Medical University, Kursk

The article presents the results of a study of the subjective pain evaluation in the structure of non-motor manifestations of Parkinson's disease (PD). In studying sensitivity the patients revealed the results indicating hypersensitivity, which was manifested both in the accurate localization of a touch, and in transferring a touch from one hand to the other. The high level of discriminatory sensitivity was also revealed. Analysis of the emotional attitude to pain and lingvosemantic signification of sensory pain in patients with PD indicates a high degree of differentiation of semantic units. The practical significance of the results is an original conception of a correlation between the subjective pain sensation, sensitivity and emotional reactions based at the level of empirical argumentation. Sensory-painful sensations are early markers of the nonmotor stage (stages I-II) of PD. Their combination with depressive manifestations makes it possible to reveal the disease manifestation in the early stages.

Keywords: Parkinson's disease, pain syndrome, nonmotor symptoms, interceptive sensations, descriptors of interceptive sensations.

На 2016 год в Российской Федерации частота встречаемости болезни Паркинсона (БП) (G20 по МКБ-10) соответствует 139,9-238 человек на 100000 населения [2]. Данная нейродегенеративная патология занимает второе место после болезни Альцгеймера (G30 по МКБ-10) [10]. БП составляет от 60 до $80 \%$ всех случаев нейродегенеративных заболеваний, имеет неблагоприятный прогноз дожития (смертельный исход составляет 40-75\%). Пациенты с БП требуют постоянного постороннего ухода, также низкой является и субъективная оценка качества их собственной жизни.

Анализ научной разработанности проблемы изучения болевых синдромов при БП в международной наукометрической базе PubMed указывает на то, что объем публикационной активности в области гистологии, фармакогнозии, физиологии и медицины составляет 1106 научных работ за 2006-2016 годы. На базе отечественной наукометрической системы Elibrary объем научных публикаций по клинико-психологическим, нейрофизиологическим и неврологическим аспектам изучения обозначенной проблематики составляет 33 статьи. Очевидным является противоречие в исследовательском пространстве изучения болевых синдромов при БП между высоким исследовательским интересом к медицинским, фармакологическим, гистологическим аспектам изучения при минимальном объеме научных публикаций по клинико-психологическим и нейрофизиологическим аспектам изучения БП.

Гибель дофаминергических нейронов стриопаллидарной системы (входящей в экстрапирамидную систему, функционально обеспечивающую организацию и построение) обусловливает многообразие клинических проявлений БП [6].

Наибольшие повреждения дофаминергических нейронов затрагивают компактную часть черной субстанции и вентральную покрышку среднего мозга. Нейроны черной субстанции дают проекции на кору больших полушарий и ба- 
зальные ганглии, образуя тем самым мезокортикальный, нигростриатный и мезолимбический проводящие пути. Часть нейронов вентральной покрышки дают проекции в лобные доли коры больших полушарий, их функция связна с принятием решений. Другая часть нейронов вентральной покрышки дает проекции в миндалину и прилежащее ядро прозрачной перегородки, их функции отвечают за потребности, мотивацию и эмоции. При болезни Паркинсона нарушения, связанные с движением, основаны на гибели дофаминергических нейронов стриатума и черной субстанции [2].

Установлено, что нейротрансмиттерные нарушения при БП не ограничиваются нарушением только дофаминергической системы (ДА). Оно затрагивает также норадренергическую (НА), серотонинергическую (5-НТ), холинергическую (ХЭ) и другие (глутамат-, ГАМК-ергические) нервные сети, локализованные не только в головном мозге, но и в спинном мозге и симпатической нервной системе [10].

Благодаря методам функциональной нейровизуализации, а именно позитронно-эмиссионной томографии, удалось обнаружить, что при снижении уровня дофамина в стриатуме на 60-80\% дебютируют моторные симптомы [3]. Следовательно, возникновение моторных проявлений обусловлено гибелью большей половины дофаминергических нейронов черной субстанции. Основу клинической картины БП составляет синдром паркинсонизма, который характеризуется мышечной ригидностью, гипокинезией и тремором покоя. По мере прогрессирования заболевания к данным симптомам присоединяются постуральные расстройства.

Кроме того, наряду с исследованиями моторных нарушений при БП в область исследований авторов попадают механизмы прогрессирования немоторных проявлений. К ним относят вегетативные нарушения, сенсорные расстройства, болевые ощущения, нарушение обоняния, повышенную потливость, изменения индекса массы тела, желудочно-кишечные расстройства, нарушения сна. Кроме того, к немоторным расстройствам относят когнитивные и аффективные нарушения, синдром дефицита внимания, сердечно-сосудистые симптомы, а также сексуальную дисфункцию [13, 17].

Развитие патологического процесса при БП, согласно классификации H. Braak, включает в себя 6 стадий, в течение которых происходят изменения: от дегенерации переднего обонятельного ядра и обонятельной луковицы (клинические проявления: нарушение обоняния (I стадия) до появления в лимбических структурах и коре головного мозга телец Леви (клинические проявления: прогрессирование поведенческих, когнитивных и психотических расстройств (V-VI стадии) [3].

В ряде случаев до появления двигательных симптомов возникают болевые синдромы. Они встречаются у 40-89\% пациентов с БП [1]. У 10\% пациентов с БП симптомом, предшествующим двигательным нарушениям, может быть боль, которая чаще всего возникает на стороне будущих моторных симптомов [8].

Особенностью болевых синдромов при БП является большая частота хронических болей различной локализации. В основном это плечо, шейный и пояснично-крестцовый отделы позвоночника, в области рта, а также гениталий. В ряде исследований авторы указывают на наличие связи интенсивности боли с депрессией, а также взаимосвязь боли с выраженностью двигательных нарушений [1]. Пациенты описывают боли как ноющие, тянущие, жгучие, покалывающие в мышцах спины, шеи, конечностей. На связь болевых проявлений с БП указывало уменьшение боли при приеме противопаркинсонических средств. Также пациенты указывали на развитие парастезий в конечностях, более выраженных в наиболее пораженных. Зачастую врачи при осмотре пациента с БП не принимают во внимание жалобы на болевые ощущения, однако чаще всего именно этот симптом является отягощающим субъективное переживание боли.

Исследования болевых ощущений при БП с учетом локализации (брюшная полость) содержат выводы о связанности таковых с фармакотерапией (в частности, с дозой принимаемой леводопы) [18]. В исследовании C.H. Lin et al. авторы делают вывод о том, что в условиях, когда нет нарушений опорно-двигательного аппарата у пациентов с БП, первичная боль может происходить либо из центральных, либо из периферических механизмов сенсорной обработки как часть процесса дегенерации [19]. Боль рассматривается в качестве раннего маркера БП на додвигательной стадии. Общими факторами болевых ощущений авторы определяют депрессию и пол. Делают вывод о том, хроническая боль является наиболее значимым показателем для качества жизни пациентов с БП [20].

На нейрофизиологическом уровне субъективное восприятие болевых ощущений связано со способностью дифференцировать данные ощущения от других сенсорных ощущений, выражая их при помощи лингвосемантических единиц. В данной работе будут рассматриваться болевые дескрипторы как лингвосемантические единицы описания субъективных телесных ощущений [9].

Качественные характеристики тактильных ощущений у пациентов с БП основываются на 
особенностях приема, передачи и переработки стимула, также оказывает значительное влияние изменение нейромедиаторного баланса. Кожнокинестетический анализатор представлен звеньями рефлекторной дуги: афферентным нейроном с длинным аксоном, который состоит из окончания чувствительных нервных волокон в коже и в мышцах; чувствительными периферическими нейронами межпозвоночных узлов; переключательными ядрами в продолговатом мозге; переключательными (реле) ядрами в зрительном бугре и кожно-кинестетической зоной коры (представленной постцентральной и теменными зонами коры больших полушарий); двигательной зоной коры (представленной прецентральной извилиной и лобными долями коры больших полушарий); пирамидным путем; эффекторным нейроном спинного мозга; двигательными нервными окончаниями в скелетных мышцах, связанными с рецепторами, содержащимися в коже и связанными с рецепторами, находящимися в мышцах, суставах и сухожилиях. В данной работе рассматриваются особенности интерацептивной и проприоцептивной чувствительности.

Обобщая наши рассуждения в рамках системно-динамической парадигмы, мы исходим из того, что у пациентов с БП проявления гиперчувствительности не относятся к специфическим проявлениям заболевания. Тем не менее нейромедиаторные нарушения дофаминергической, норадренергической и серотонинергической систем при БП, приводящие к снижению порогов тактильной чувствительности, усиливают субъективные болевые ощущения, а следовательно, ведут к ухудшению субъективного переживания качества жизни.

Целью исследования выступает изучение субъективной оценки боли в структуре немоторных проявлений БП.

\section{МАТЕРИАЛЫ И МЕТОДЫ ИССЛЕДОВАНИЯ}

Общий объем выборки составил 29 человек в возрасте от 62 до 75 лет (средний возраст пациентов составлял $64,29 \pm 4,42$ года). В экспериментальную группу вошли 12 пациентов с диагнозом G20 «Болезнь Паркинсона» (по МКБ-10) с длительностью заболевания 6-8 лет. Все пациенты в качестве терапии получали препараты леводопы (средняя доза составляла 592,2+276,2 мг/сут); $54 \%$ пациентов получали агонисты дофаминовых рецепторов (перибедил или прамипексол); 46\% пациентов принимали амантадин. В контрольную группу вошли 17 испытуемых с отсутствием хронических заболеваний со стороны дыхательной, эндокринной и сердечно-сосудистой системы.
Исследовательские группы уравнивались по полу (все испытуемые - мужчины) и уровню образования (все испытуемые имеют среднеспециальное образование). Исследование испытуемых проводилось на условиях информированного согласия.

Схема исследования включала два аспекта: клиническое обследование, проводимое врачомневрологом; клинико-психологическое исследование, проводимое клиническим психологом.

Клиническое обследование включало в себя оценку объективного неврологического и соматического статусов (шкала Хена и Яра для установления стадии заболевания [16]; шкала UPDRS для оценки степени тяжести двигательных нарушений [12]; опросник НMC и анкета НMC для оценки выраженности немоторных проявлений БП [15]), анамнеза жизни и анамнеза заболевания (клиническая беседа, архивный метод - анализ медицинской документации).

Клинико-психологическое исследование включало в себя оценку объективного исследования порога болевой чувствительности (метод прессальгометрии) [7], субъективную оценку интенсивности боли (визуальная аналоговая шкала ВАШ) [4], оценку тактильной чувствительности (набор функциональных нейропсихологических проб) [5], оценку семантического означивания дескрипторов болевых ощущений (методика «Выбор дескрипторов интрацептивных ощущений» (А.Ш. Тхостов), многомерный вербальноцветовой болевой тест) [8].

Прессальгометрия представляет собой метод объективного исследования порога болевой чувствительности. Процедура данного метода состоит в том, что на плечо пациента надевалась манжетка, на внутренней поверхности которой укреплен игольчатый аппликатор. При нагнетании в нее воздуха у пациента возникает болевое ощущение. Количественный показатель порога болевой чувствительности оценивался по давлению в манжетке (в мм рт. ст.) в момент восприятия боли [7].

Использование функциональных нейропсихологических проб для исследования сложных видов чувствительности (проба на исследование локализации прикосновений, проба Тойбера, проба на перенос прикосновения с одной руки на другую, оценка дискриминационной чувствительности (тест Вебера)) [5], диагностирующих корковый уровень, обусловлено, тем, что оценка чувствительности на данном уровне подлежит дифференцированной субъективной оценке. Процедура проведения функциональных нейропсихологических проб исследования чувствительности представлена в таблице 1. 
Таблица 1

Процедура проведения функциональных нейропсихологических проб исследования чувствительности

\begin{tabular}{|c|c|}
\hline Проба & Процедура \\
\hline $\begin{array}{l}\text { Проба на } \\
\text { локализацию } \\
\text { прикосновений }\end{array}$ & $\begin{array}{l}\text { Пациента просят показать точку локализации прикосновения на тыльной стороне } \\
\text { ладони. Оценивается точность локализации прикосновения и сравнивается } \\
\text { успешность выполнения задания с разных сторон. Точность локализации } \\
\text { прикосновений оценивалась по количеству допущенных ошибок (за ошибку } \\
\text { принималось смещение точки прикосновения более чем на } 15 \text { мм). }\end{array}$ \\
\hline Проба Тойбера & $\begin{array}{l}\text { При одновременном прикосновении к двум точкам на теле пациента (к обеим } \\
\text { рукам), ему необходимо показать точки локализации прикосновений. Важно } \\
\text { учитывать оба прикосновения, так как проба направлена на выявление феномена } \\
\text { игнорирования в тактильной сфере. Точность локализации прикосновений } \\
\text { оценивалась по количеству допущенных ошибок (за ошибку принималось смещение } \\
\text { точки прикосновения более чем на } 15 \text { мм). }\end{array}$ \\
\hline $\begin{array}{l}\text { Проба на перенос } \\
\text { прикосновения с } \\
\text { одной руки на } \\
\text { другую }\end{array}$ & $\begin{array}{l}\text { Последовательно на тыльной стороне ладони пациента указывается прикосновение в } \\
\text { стандартных точках: близко к ногтевому ложу } 2-5 \text {-го пальцев и выше - на } 1 \text {-м } \\
\text { пальце, в } 3 \text { точках по линии, соединяющей конец } 1 \text {-го пальца с наружным краем } \\
\text { лучезапястного сустава, и в } 2 \text { точках выше сустава. Пациенту после каждого } \\
\text { прикосновения необходимо находить тождественную точку на противоположной } \\
\text { руке (время реакции фиксируется). }\end{array}$ \\
\hline $\begin{array}{l}\text { Оценка } \\
\text { дискриминационной } \\
\text { чувствительности } \\
\text { (Тест Вебера) }\end{array}$ & $\begin{array}{l}\text { Исследовалась чувствительность ладонной поверхности пальцев. Для этого } \\
\text { происходила фиксация ладонной поверхности, чтобы исключить возбуждение } \\
\text { мышечно-суставных рецепторов. Осуществлялось одновременное прикосновение } \\
\text { к коже обеими ножками циркуля, концы которых нажимали с одинаковой силой, } \\
\text { такой, чтобы не вызывать появление белых пятен кожи вокруг ножек циркуля. }\end{array}$ \\
\hline
\end{tabular}

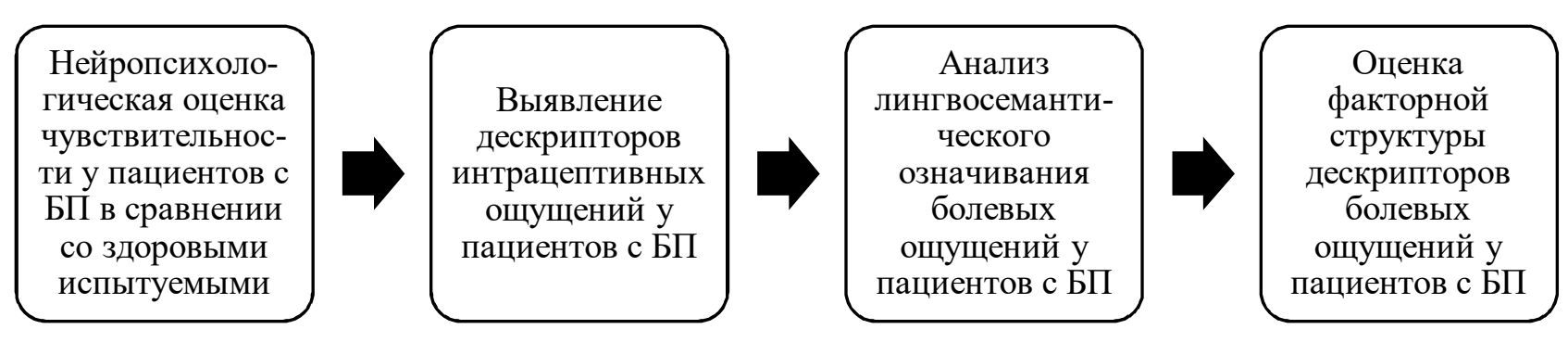

Рис. 1. Этапы исследования субъективной оценки боли в структуре немоторных проявлений БП.

Статистическая обработка полученных эмпирических данных осуществлялась с использованием методов описательной статистики (показатели средних значений, мода, медиана, среднее квадратическое отклонение), сравнительной статистики (непараметрический критерий МаннаУитни, угловое преобразование $\varphi$-Фишера), многомерной статистики (факторный анализ с varyтах-вращением).

Исследование осуществлялось последовательно в четыре этапа (рис. 1).

\section{РЕЗУЛЬТАТЫ ИССЛЕДОВАНИЯ И ИХ ОБСУЖДЕНИЕ}

В результате клинического обследования у всех пациентов с БП выявлены немоторные симп- томы: болевые ощущения (у 77\%), сонливость (у $51 \%$ ), инсомния (у 49\%), симптом беспокойных ног (у 41\%), парестезии (у 61\%), а также запоры (у $57 \%$ ) и нарушения мочеиспускания (у $49 \%$ ). В результате исследования установлено, что степень выраженности немоторных проявлений коррелирует со стадией БП по шкале Хена и Яра. Одним из наиболее часто встречающихся немоторных симптомов БП является боль (77\%).

Выраженность двигательных нарушений в конечностях и аксиальных двигательных нарушений, оцениваемых по III (двигательной) части UPDRS, была выше у больных на развѐрнутой стадии болезни Паркинсона. Установлено, чем выше у пациентов с БП выраженность двигательных расстройств по III (двигательной) части UPDRS, тем более выражены болевые ощущения. 
Скелетно-мышечные боли при БП возникают при нарушении биомеханики двигательного акта вследствие постуральных и других двигательных нарушений, а также изменений мышечного тонуса; описываются пациентами как ноющие, ломящие боли, судороги. Боли центрального механизма, описываемые пациентами как жгучие боли, ощущения «покалывания, пощипывания, ползания мурашек», возникают вследствие нарушения центральных механизмов сенсорной обработки вследствие процесса дегенерации. Также отмечалась зависимость проявления интенсивности боли от депрессивных и тревожных показателей, способствующих снижению болевого порога (по опроснику НMC у всех пациентов с развитием болевого синдрома отмечались депрессия или тревога).

Полученные результаты свидетельствуют о том, что чем более выражены двигательные нарушения, тем выше интенсивность и дифференцированность болевых ощущений.

В результате исследования чувствительности у пациентов с БП выявлено проявление гиперчувствительности в конечности, противоположной локализации очагу поражения. Точность локализации прикосновений у пациентов с БП в преобладающем большинстве случаев $(69,2 \%)$ определяется в диапазоне значений до 10 мм. (при значениях нормативных показателей до 15 мм). При отсутствии БП (в группе здоровых испытуемых) точность локализации прикосновений в 52,6\% случаев определяется в границах от 10 до 15 мм (рис. 2).

При исследовании у пациентов с БП узнавания одновременного прикосновения к обеим рукам с помощью пробы Тойбера установлено отсутствие феномена игнорирования в тактильной сфере. В 95,5\% случаев пациенты с БП фиксируют два прикосновения (при одновременном прикосновении к обеим рукам. У пациентов с отсутствием БП отсутствие феномена игнорирования в тактильной сфере выявлено в $100 \%$ случаев.

Точность переноса прикосновения с одной руки на другую у пациентов с БП колеблется в диапазоне до 3 мм в 94\% случаев, в то время как у здоровых испытуемых точность переноса прикосновения в указанном диапазоне установлена лишь в $4,6 \%$ случаев.

Оценка дискриминационной чувствительности осуществлялась с использованием циркуля Вебера, В результате исследования у $63,2 \%$ испытуемых с БП диапазон различительной чувствительности, определяемой как минимальное расстояние, при одновременном прикосновении к участку кожи, при котором пациент воспринимает данное прикосновение как две различные точки, составляет до 3 мм. У испытуемых с отсутствием БП (здоровых) более чем в половине случаев $(56,2 \%)$ дифференциация двух прикосновений осуществляется при расстоянии между браншами циркуля от 3 до 5 мм (рис. 3).

В результате исследования дискриминационной чувствительности у пациентов с БП установлено, что диапазон различения двух прикосновений составляет 1,1-1,3 мм вне зависимости от места локализации (ладонная поверхность кончиков пальцев, центральная часть ладонной поверхности, тыльная сторона ладони) (рис. 4).

Таким образом, в результате исследования чувствительности у пациентов с БП выявлены проявления гиперчувствительности при точности локализации и дифференцированности двух прикосновений.

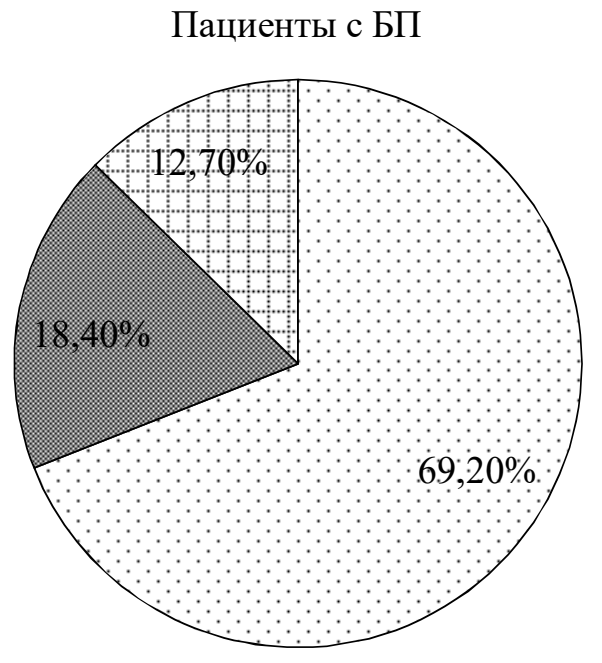

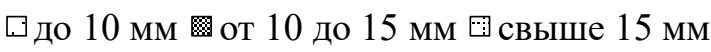

Здоровые испытуемые

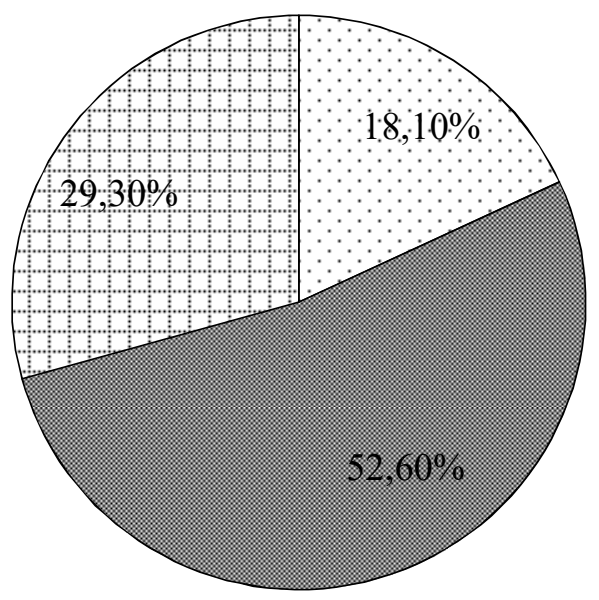

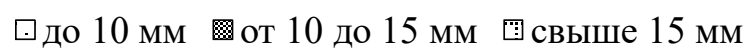

Рис. 2. Диаграммы долевого распределения диапазонов определения локализации прикосновений у пациентов с БП и здоровых испытуемых. 


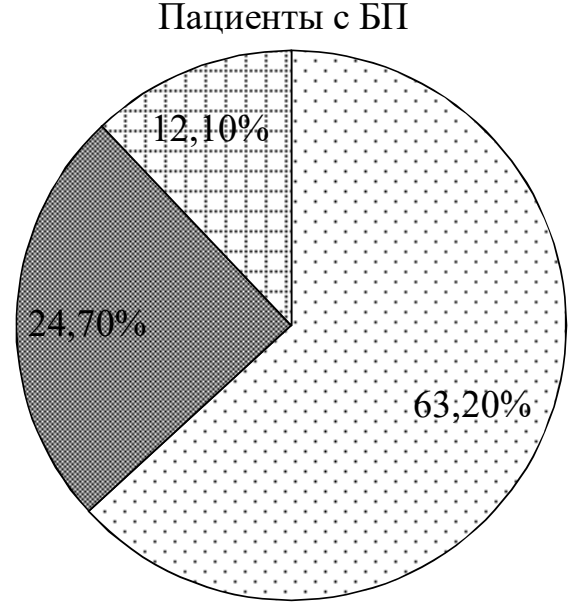

๑до 3 мм 뭉 от 3 до 5 мм свыше 5 мм
Здоровые испытуемые

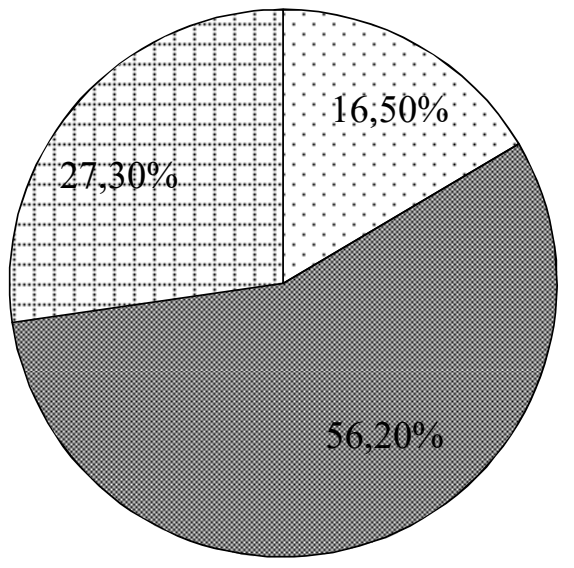

口до 3 мм 圆 от 3 до 5 мм 뿡ше 5 мм

Рис. 3. Диаграммы долевого распределения диапазонов различительной чувствительности у пациентов с БП и здоровых испытуемых.

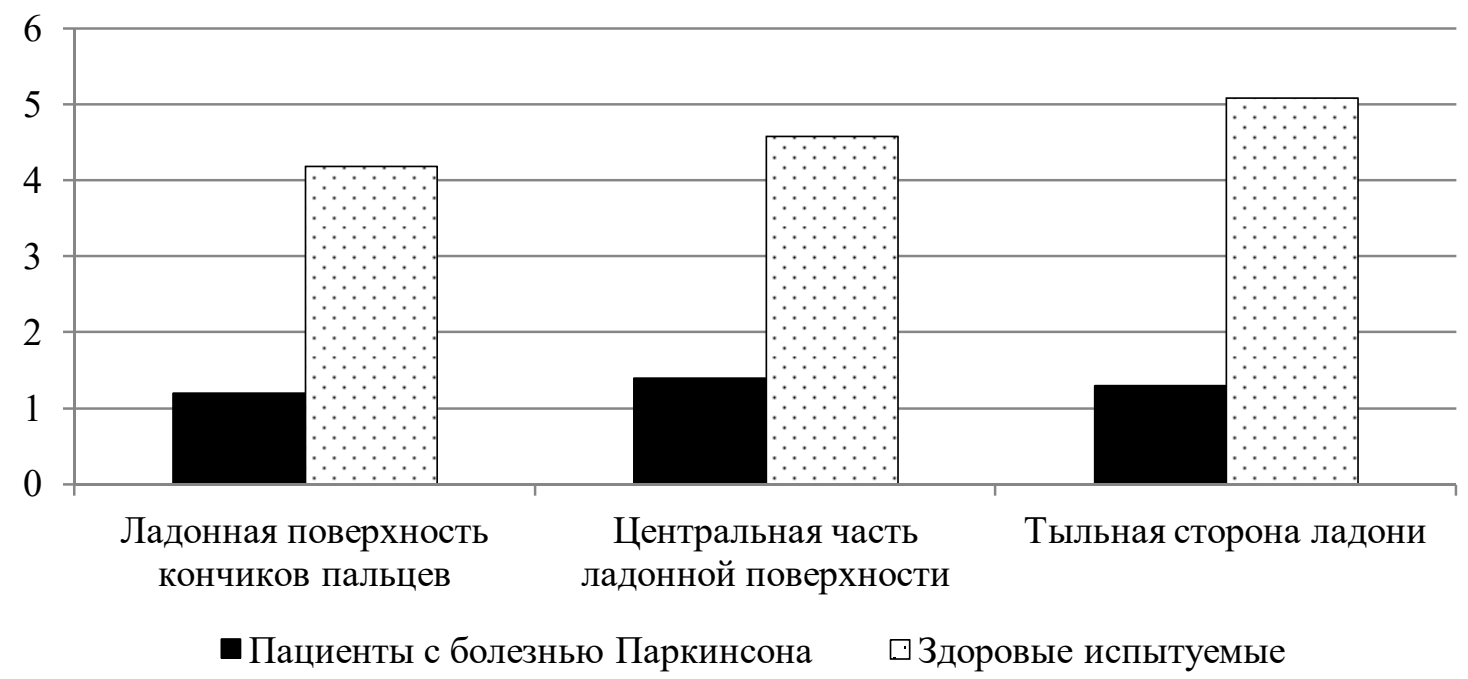

Рис 4. Гистограмма оценки абсолютных значений дискриминационной чувствительности у пациентов с болезнью Паркинсона (расстояние в мм между ножками циркуля).

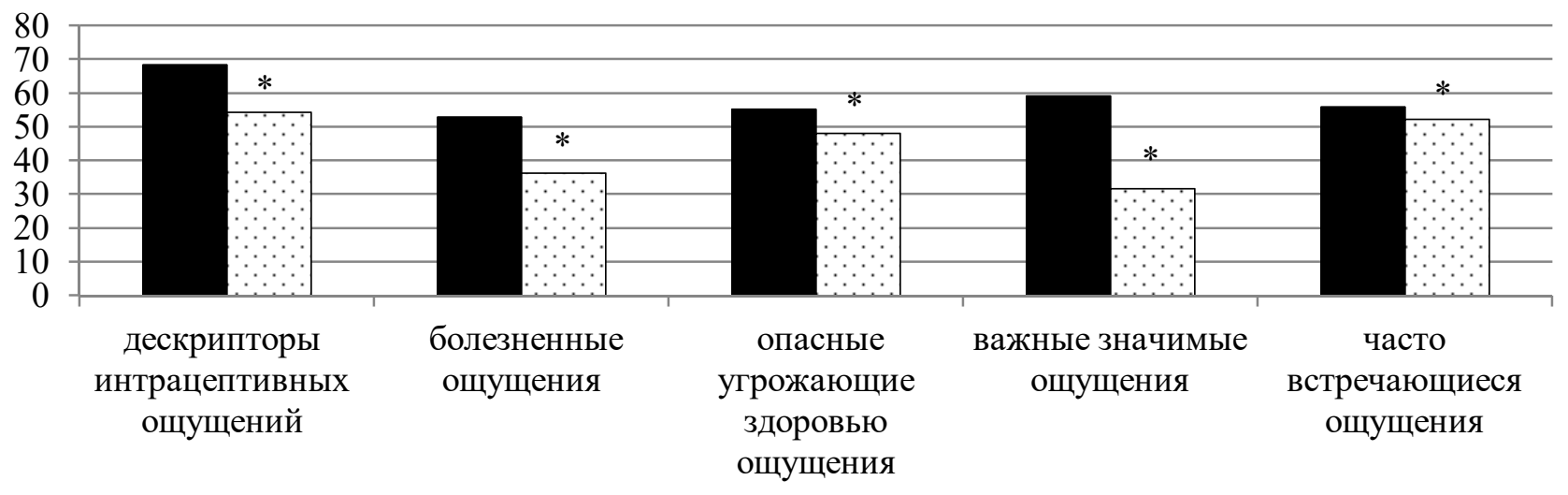

-Пациенты с болезнью Паркинсона ஏЗдоровые испытуемые

Рис 5. Гистограмма средних значений количества дескрипторов интрацептивных ощущений у пациентов с БП.

Примечание: * $-\mathrm{p} \leq 0,05$. 
Частота выбора дескрипторов интрацептивных ощущений у пациентов с БП с учетом интенсивности болевых ощущений

\begin{tabular}{|c|c|c|}
\hline \multirow[t]{2}{*}{ Класс } & Средняя частота выборов & \multirow{2}{*}{$\begin{array}{c}\text { Уровень значимости различий р } \\
\text { (ф-критерий Фишера) }\end{array}$} \\
\hline & Пациенты с БП & \\
\hline \multicolumn{2}{|c|}{ Классификачия «части речи» } & \\
\hline Глаголы & 56,37 & 0,026 \\
\hline Существительные & 64,01 & 0,019 \\
\hline Наречия & 54,29 & 0,028 \\
\hline Прилагательные & 46,58 & 0,028 \\
\hline Причастия & 55,39 & 0,021 \\
\hline \multicolumn{2}{|c|}{ Классификачия «частотность» } & \\
\hline Низкочастотные & 35,84 & 0,031 \\
\hline Среднечастотные & 59,63 & 0,026 \\
\hline Высокочастотные & 76,94 & 0,028 \\
\hline \multicolumn{2}{|c|}{ Классификачия «модальность» } & \\
\hline Положительная & 9,60 & 0,074 \\
\hline Отрицательная & 84,57 & 0,024 \\
\hline
\end{tabular}

Решая задачу исследования дескрипторов интрацептивных ощущений у пациентов с БП, выявлено статистически значимое увеличение общего количества дескрипторов $(\mathrm{p}=0,024)$ с преобладанием важных, значимых ощущений $(p=0,031)$ и угрожающих здоровью, опасных ощущений $(\mathrm{p}=0,016)$ (рис. 5).

Анализ лингвосемантического означивания болевых ощущений у пациентов с БП осуществлялся посредством оценки дескрипторов интрацептивных ощущений.

На этапе анализа лингвосемантического означивания болевых ощущений у пациентов с БП через оценку дескрипторов интрацептивных ощущений был осуществлен расчет показателей средней частоты выборов дескрипторов по лингвосемантическим единицам по трем классификационным группам: «части речи», «частотность» и «модальность» (таблица 2).

Анализ соотношения сенсорных ощущений боли и характеристик эмоционального отношения к боли у пациентов с БП осуществлялся с учетом субъективной оценки выраженности боли. Пациенты с БП по критерию субъективной оценки интенсивности боли были разделены на две группы: пациенты с очень сильной, нестерпимой болью, соответствующей в количественном выражении 8-10 баллам (24\% испытуемых); пациенты, описывающие болевые ощущения как сильные, оцениваемые в 6-7 баллов ( $76 \%$ испытуемых).

В результате исследования выявлено значимое увеличение количества дескрипторов $(\mathrm{p}=0,029)$ у пациентов с БП с очень высокой оценкой интенсивности болевых ощущений в сравнении с пациентами, характеризующимися интенсивностью болевых ощущений. При этом у пациентов с БП профиль лингвосемантического означивания дескрипторов по критерию сенсорного ощущения боли характеризуется преобладанием пронзающей, ноющей, стреляющей, монотонной боли; по критерию эмоционального отношения к боли - преобладанием надоедливой, мучающей и беспокоящей боли. При этом у пациентов с БП со сверхсильной интенсивностью болевых ощущений общее количество дескрипторов сенсорного ощущения боли меньше, чем количество дескрипторов, характеризующих эмоциональное отношение к боли, что указывает на высокую дифференцированность эмоционального отношения к боли и низкую дифференцированность сенсорного ощущения боли (рис. 6).

Обобщая полученные результаты исследования дескрипторов интрацептивных ощущений у пациентов с БП, выявлен высокий уровень дифференцированности болевых ощущений (что также проявляется в высокой степени дифференцированности семантических единиц) и эмоционального отношения к ним. Установлено, что при преобладании болезненных ощущений общее количество дескрипторов интрацептивных ощущений значимо выше в сравнении со здоровыми испытуемыми. Эмпирически доказано, что высокая интенсивность болевых ощущений снижает дифференциацию сенсорного ощущения боли, тем самым повышая значимость эмоционального отношения.

Осуществляя оценку факторной структуры дескрипторов болевых ощущений у пациентов с БП с учетом субъективной оценки интенсивности болевых ощущений, выявлена трехфакторная структура (табл. 3 ). 


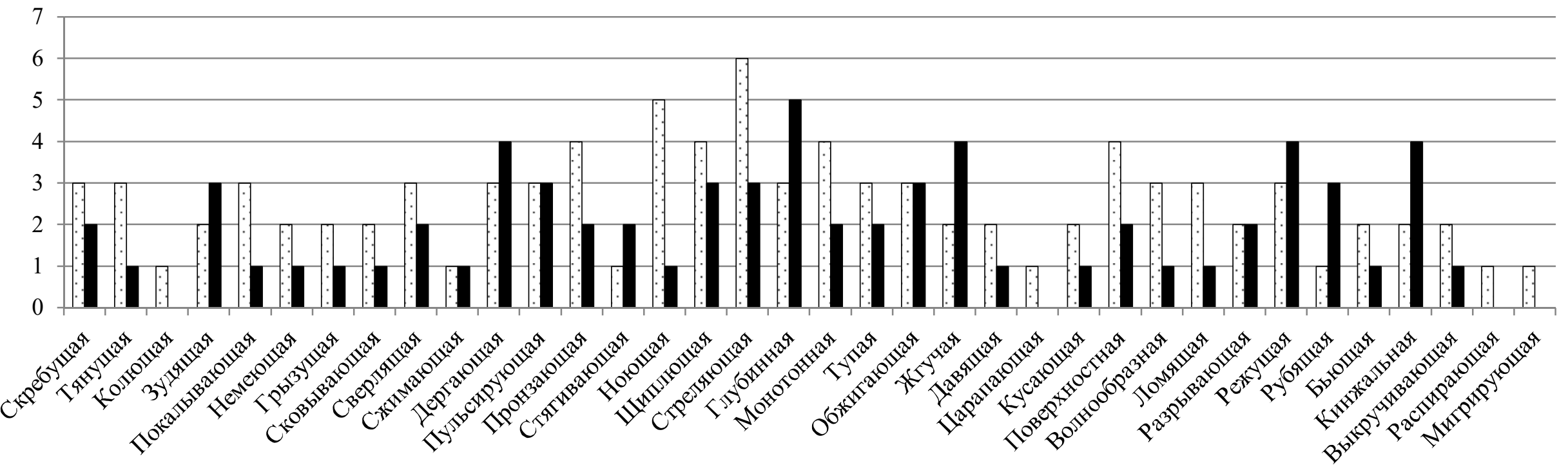

घСльная интенсивность болевых ощущений Сверхсильная интенсивность болевых ощущений

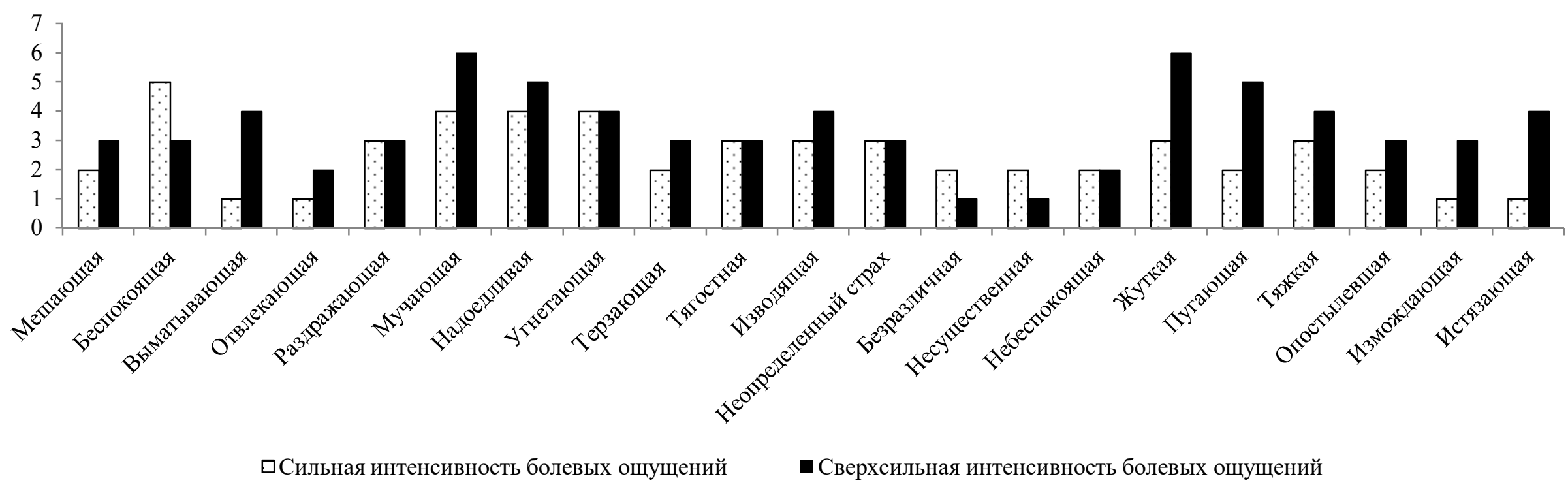

Рис. 6. Профили частот лингвосемантического означивания сенсорного ощущения боли и эмоционального отношения к боли у пациентов с БП. 
Факторная структура дескрипторов болевых ощущений у пациентов с БП с учетом субъективной оценки интенсивности болевых ощущений

\begin{tabular}{|c|c|c|c|}
\hline \multicolumn{2}{|c|}{$\begin{array}{c}\text { Сверхсильная } \\
\text { интенсивность болевых ощущений } \\
\end{array}$} & \multicolumn{2}{|c|}{$\begin{array}{c}\text { Сильная } \\
\text { интенсивность болевых ощущений } \\
\end{array}$} \\
\hline \multirow[t]{2}{*}{$\begin{array}{l}\text { Первый } \\
\text { фактор }\end{array}$} & Локализация прикосновений $(\mathbf{0 , 7 3 2})$ & \multirow[t]{2}{*}{$\begin{array}{l}\text { Первый } \\
\text { фактор }\end{array}$} & $\begin{array}{c}\text { Субъективная оценка интенсивности } \\
\text { болевых ощущений }(\mathbf{0 , 7 3 8 )}\end{array}$ \\
\hline & $\begin{array}{c}\text { Эмоциональное отношение к боли } \\
(\mathbf{0 , 8 0 4 )}\end{array}$ & & $\begin{array}{c}\text { Угрожающие здоровью, опасные } \\
\text { ощущения (0,722) }\end{array}$ \\
\hline \multirow[t]{2}{*}{$\begin{array}{l}\text { Второй } \\
\text { фактор }\end{array}$} & $\begin{array}{c}\text { Субъективная оценка интенсивности } \\
\text { болевых ощущений }(\mathbf{0 , 8 1 6 )}\end{array}$ & \multirow[t]{2}{*}{$\begin{array}{l}\text { Второй } \\
\text { фактор }\end{array}$} & $\begin{array}{c}\text { Дискриминационная чувствительность } \\
(\mathbf{0 , 8 3 6 )}\end{array}$ \\
\hline & $\begin{array}{c}\text { Дискриминационная чувствительность } \\
(\mathbf{0 , 7 7 4 )}\end{array}$ & & Эмоциональное отношение к боли $(\mathbf{0 , 7 2 7})$ \\
\hline \multirow[t]{2}{*}{$\begin{array}{l}\text { Третий } \\
\text { фактор }\end{array}$} & $\begin{array}{c}\text { Субъективная оценка интенсивности } \\
\text { болевых ощущений }(\mathbf{0 , 7 5 8})\end{array}$ & \multirow[t]{2}{*}{$\begin{array}{l}\text { Третий } \\
\text { фактор }\end{array}$} & Различительная чувствительность $(\mathbf{0 , 7 4 4 )}$ \\
\hline & $\begin{array}{c}\text { Сенсорная оценка болевых ощущений } \\
(\mathbf{0 , 7 5 9 )}\end{array}$ & & $\begin{array}{c}\text { Сенсорная оценка интенсивности болевых } \\
\text { ощущений }(\mathbf{0 , 7 6 4 )}\end{array}$ \\
\hline
\end{tabular}

У пациентов с БП со сверхсильной интенсивностью болевых ощущений первый фактор с максимальной факторной нагрузкой включает показатели локализации прикосновений $(0,732)$ и показатели дескрипторов эмоционального отношения к боли $(0,804)$; второй фактор представлен показателями субъективной оценки интенсивности болевых ощущений $(0,816)$ и дискриминационной чувствительностью $(0,774)$; в третий фактор входят показатели субъективной оценки интенсивности болевых ощущений $(0,758)$ и показатели дескрипторов сенсорной оценки болевых ощущений $(0,759)$. При сильной интенсивности болевых ощущений первый фактор с основной факторной нагрузкой представлен показателями субъективной оценки интенсивности болевых ощущений $(0,738)$ и показателями дескрипторов угрожающих здоровью, опасных ощущений $(0,722)$, второй фактор включает показатели дискриминационной чувствительности $(0,836)$ и дескрипторы эмоционального отношения к боли $(0,727)$, в третий фактор входят показатели различительной чувствительности $(0,744)$ и дескрипторы сенсорной оценки интенсивности болевых ощущений $(0,764)$.

Полученные результаты оценки факторной структуры дескрипторов болевых ощущений у пациентов с БП с учетом субъективной оценки интенсивности болевых ощущений свидетельствуют о том, что высокая интенсивность болевых ощущений определяет степень дифференцированности дескрипторов интрацептивных ощущений как на эмоциональном, так и на сенсорном уровне. Чем выше интенсивность болевых ощущений (по субъективным оценкам), тем выше степень дифференцированности дескрипторов эмоционального отношения к боли и тем ниже дифференцированость сенсорной оценки болевых ощущений.

Нейромедиаторные нарушения дофаминергической, норадренергической и серотонинергической систем у пациентов с БП приводят к снижению порогов тактильной чувствительности, что, в свою очередь, приводит к усилению субъективных болевых ощущений. Выявленные в работе признаки гиперчувствительности у пациентов с БП соотносятся с выводами о том, что пациенты с невропатическими болями при БП имеют более низкий порог чувствительности и чаще испытывают боль в сравнении с пациентами с БП без невропатических болей [14].

Практическая значимость результатов проведенного исследования заключается в том, что впервые на уровне эмпирической аргументации представлена взаимосвязь субъективного ощущения боли, чувствительности и эмоциональных реакций. Сенсорно-болевые ощущения являются ранними маркерами домоторной стадии (I-II стадии) БП. Их сочетанность с депрессивными проявлениями позволяет выявить манифестацию заболевания на ранних этапах. Это - с одной стороны, с другой же - в процессе клиникопсихологического сопровождения сенсорноболевые ощущения выступают в качестве мишени психокоррекционного воздействия, ориентированного на снижение субъективной компоненты болевых ощущений.

\section{ЛИТЕРАТУРА}

1. Алексеев А., Нодель М., Подчуфарова Е. Болевые синдромы у пациентов с болезнью Паркинсона // Врач. - 2012. - № 7. - С. 85-88.

2. Байрамукова А.М., Ажахметова А.К., Карпов С.М. Эпидемиология болезни Паркинсона в различных 
странах мира // Успехи современного естествознания. -2013 . - № 9. - С. 20-21.

3. Богданов P.P. Особенности лекарственной терапии начальных проявлений болезни Паркинсона // Нервные болезни. - 2013. - № 1. - С. 2-5.

4. Бывальцев В.А., Бельх Е.Г., Алексеева Н.В., Сороковиков B.A. Применение шкал и анкет в обследовании пациентов с дегенеративным поражением поясничного отдела позвоночника: методические рекомендации - Иркутск : ФГБУ «НЦРВХ» СО PAMH, 2013. - 32 c.

5. Вассерман Л.И., Дорофеева С.А., Меерсон Я.А. Методы нейропсихологической диагностики. СПб. : Стройлеспечать, 1997. - 360 с.

6. Курушина О.В., Барулина А.Е., Радюк М.А. Болезнь Паркинсона: современные взгляды на этиологию, патогенез, диагностику и лечение // Лекарственный вестник. - 2014. - № 2. - С. 3-8.

7. Левин О.С., Махнев С.О. Болевые синдромы при болезни Паркинсона // Альманах клинической медицины. - 2006. - № 13. - С. 130-134.

8. Никишина В.Б., Бобынцеев И.И., Петраш Е.А., Миняхина К.A. Дескрипторы интрацептивных ощущений при фантомно-болевом синдроме у людей с ампутацией нижних конечностей // Курский научно-практический вестник «Человек и его здоровье». - 2015. - № 3. - С. 133-139.

9. Пугачева В.С., Карпов С.М., Вышлова И.А., Муравьев К.A. Болезнь Паркинсона: распространенность заболевания с точки зрения медицинской статистики // Бюллетень науки и практики. 2016. - № 5. - С. 193-204.

10. Тропникова Г.К. Болезнь Паркинсона и серотонин // Вести национальноый академии наук Беларуси. Серия медицинских наук. - 2012. - № 1. C. $95-108$.

11. Тхостов А.Ш. Психология телесности. - М. : Смысл, 2002. - 287 с.

12. Унифицированная шкала оценки болезни Паркинсона Международного общества расстройств движений (MDS UPDRS) // http://medqueen.com/medicina/diagnostika/diagnostik a-statya/590-shkala-ocenki-bolezni-parkinsona.html
13. Berganzo K., Tijero B., González-Eizaguirre A., Somme J., Lezcano E., Gabilondo I., Fernandez M., Zarranz J.J., Gómez-Esteban J.C. Motor and nonmotor symptoms of Parkinson's disease and their impact on quality of life and on different clinical subgroups // Neurologia. - 2016. - Vol. 31, N 9. P. 585-591. - doi: 10.1016/j.nrl.2014.10.010.

14. Brefel-Courbon C., Ory-Magne F., Thalamas C., Payoux $P$., Rascol $O$. Nociceptive brain activation in patients with neuropathic pain related to Parkinson's disease // Parkinsonism Relat Disord. - 2013. Vol. 19, N 5. - P. 548-552. - doi: 10.1016/j.parkreldis.2013.02.003

15. Global Parkinson's Disease Survey Steering Committee. Factors impacting on quality of life in Parkinson's disease: results from an international survey // Mov Disord. - 2002. - Vol. 17, N 1. - P. 60-67.

16. Hoehn M.M., Yahr M.D. Parkinsonism: onset, progression and mortality // Neurology. - 1967. Vol. 17, N 5. - P. 427-442. - doi: 10.1212/WNL.17.5.427.

17. Hou J.-G.G., Lai E.C. Non-motor Symptoms of Parkinson's Disease // International Journal of Gerontology. - 2007. - Vol. 1, N 2. - P. 53-64. - doi: 10.1016/S1873-9598(08)70024-3.

18. Kataoka H., Sawada Y., Namizaki T., Shimozato N., Yoshiji H., Ueno S. Intrajejunal Infusion of LevodopaCarbidopa Gel Can Continuously Reduce the Severity of Dropped Head in Parkinson's Disease // Front Neurol. - 2017. - Vol. 8. - P. 547. - doi: 10.3389/fneur.2017.00547.

19. Lin C.H., Wu R.M., Chang H.Y., Chiang Y.T., Lin H.H. Preceding pain symptoms and Parkinson's disease: a nationwide population-based cohort study // Eur J Neurol. - 2013. - Vol. 20, N 10. - P. 1398-1404. doi: 10.1111/ene.12197.

20. Ozturk E.A., Gundogdu I., Kocer B., Comoglu S., Cakci A. Chronic pain in Parkinson's disease: Frequency, characteristics, independent factors, and relationship with health-related quality of life // J Back Musculoskelet Rehabil. - 2016 - doi: 10.3233/BMR160720. 